\title{
STUDY OF MELANOMA CELL BEHAVIOR IN VITRO \\ IN COLLAGEN FUNCTIONALIZED BACTERIAL NANOCELLULOSE HYDROGELS
}

\author{
MAÍRA DE ANDRADE PEIXOTO, EMILY MARQUES DOS REIS, KARINA CESCA and LUISMAR \\ MARQUES PORTO \\ LiEB - Biological Engineering Laboratory, Chemical and Food Engineering Department, \\ Federal University of Santa Catarina, Florianópolis, SC, Brazil \\ $\bowtie$ Corresponding author: M. de Andrade Peixoto, mairapeixoto@intelab.ufsc.br
}

Received November 22, 2019

\begin{abstract}
Melanoma is a type of cancer that develops from melanin-producing cells - the melanocytes. Melanoma has a low incidence, but a high mortality rate. This is because of its great ability to cause metastasis. This study aims to develop human melanoma cell spheroids (SK-MEL-28) and co-cultivate these spheroids with human umbilical vein endothelial cells (HUVECs) in type I collagen-modified bacterial nanocellulose hydrogels (BNC-COL). The results presented here indicate that the presence of collagen in BNC-COL results in higher cell adhesion, when compared to pure bacterial nanocellulose (BNC). Human melanoma cells have demonstrated the ability to form tumor spheroids when cultured in agarose molds. The spheroids were then cultured in BNC-COL, together with HUVEC cells, for cell adhesion and migration assessment. The development of this platform has shown promise, especially for the screening of anticancer drugs.
\end{abstract}

Keywords: tumor spheroids, bacterial nanocellulose, collagen

\section{INTRODUCTION}

Melanoma is the most serious form of skin cancer because of its aggressive behavior. It is characterized by abnormal and uncontrolled growth of melanin-producing cells - the melanocytes. ${ }^{1}$ Melanoma can occur on any part of the skin or mucous membranes and appears in the form of blemishes, spots or signs. ${ }^{2}$ In Brazil alone, over 6,260 new cases of melanoma are estimated each year, with $53 \%$ in women. ${ }^{1}$ Melanoma is the deadliest form of skin cancer and its incidence continues to increase each year, accounting for over $80 \%$ of skin cancer deaths today. ${ }^{3}$ Melanoma mortality is directly linked to its high capacity to develop metastasis. ${ }^{4}$

Metastasis is characterized by the growth of tumors and invasion of adjacent tissues through the formation of blood vessels, called angiogenesis. ${ }^{5}$ Angiogenesis is the formation of new blood vessels from the pre-existing vessels and is one of the fundamental processes for tumor development, because the tumor sends chemical signals, thus stimulating the development of new blood vessels that reach it carrying the tumor blood (nutrients and oxygen). ${ }^{6}$

For the establishment of metastasis and other processes, there are numerous microenvironmental signals involved. The microenvironment of melanoma cells involves fibroblasts, keratinocytes (early stage), endothelial cells, and immune cells, which provide a rich repertoire of secreted molecules. ${ }^{4}$

Over the last few years, there has been a lot of research involving the development of new antitumor activity drugs. ${ }^{7,8,9}$ These studies allowed a better understanding of the behavior of tumor cells, especially in 3D cell cultures, such as spheroids. Spheroids are three-dimensional quasispherical cell aggregates. Their shape is especially useful in cancer research because spheroids exhibit different cellular behaviors than those known in monolayer cultures. ${ }^{10}$ Threedimensional models of multicellular tumor spheroids (MCTS) most closely resemble solid tumors in vivo, and thus provide valuable tools for in vitro identification of possible antineoplastic 
pharmacological targets. ${ }^{10}$ Multicellular tumor spheroids (MCTS) are the most widely used in vitro 3D model for preclinical oncology research, and their predictive power of the in vivo efficacy of various chemotherapeutic agents has been clearly proven. ${ }^{11-14}$

In vitro assays show endothelial cell adhesion, migration, proliferation and tubulogenesis in response to exogenous inhibiting or stimulating agents. ${ }^{7,15}$ Many of these assays are performed on commercial extracellular matrices (ECM), such as Matrigel ${ }^{\circledR}$ and Geltrex ${ }^{\circledR} .^{16,17}$

These matrices are of animal origin, their main components are laminin, collagen IV, entactin and heparin sulfate proteoglycans, and their composition may vary from batch to batch. Through these commercial matrices, it is possible to generate chemical and mechanical clues essential for cellular behavior analysis, but the results obtained with their use are inconsistent because of their intrinsic variability. ${ }^{18,19}$

An alternative to the use of the mentioned commercial matrices is represented by some peculiar types of natural and synthetic hydrogels. Hydrogels are able promote dynamic microenvironments, very similar to extracellular matrices, and assist in regulating the fate of cells through cell-cell or cell-matrix interactions. ${ }^{20,21}$

Bacterial nanocellulose (BNC) belongs to hydrogels that resemble the morphology of native ECM and is secreted by bacteria of the genus Gluconacetobacter with hydrophilic nanofiber structure. ${ }^{22}$ The composition of $\mathrm{BNC}$ is predominated by glucose monomers with $\beta$ (1-4) glycosidic bonds. ${ }^{23}$ Thanks to its structure, BNC has unique properties, such as water retention capacity, porosity, biocompatibility, and mechanical strength. ${ }^{24}$

The microscale morphological similarity of BNC hydrogel with native ECM, together with the incorporation of bioactive molecules, such as collagen, configures an appropriate 3D environment to support adhesion, proliferation, differentiation and angiogenesis. ${ }^{25}$ Such macromolecular architectures could be able to emulate and partially substitute commercial test platforms, such as Matrigel $\AA$, Geltrex $\AA$, or Millicell®. ${ }^{25}$

Collagen has high biocompatibility and low immunogenicity, being one of the most often chosen proteins for the preparation of biomaterials dedicated to ECM substitution. ${ }^{26}$ Collagen is the main ECM fibrillar protein in animal tissues, such as bones and skin, and comprises $25 \%$ of the total dry weight of mammals. ${ }^{26}$ This is why collagen scaffolds are used to study in vitro cellular behavior, such as migration and proliferation, including the invasive character of tumor cells and the interaction between cancer cells and other cell types in 3D cells culture. ${ }^{27,28}$ Such 3D environments can still be used for anti-cancer drug testing, focusing on anti-angiogenic action. ${ }^{27,28}$

In this context, the present work aims to develop an experimental platform for in vitro testing of antitumor drugs. The platform results from the co-cultivation of melanoma cell spheroids (SK-MEL-28) and human umbilical vein endothelial cells (HUVEC) in type I collagen functionalized BNC scaffolds.

\section{EXPERIMENTAL}

\section{Bacterial nanocellulose production}

The bacterial strain used was Gluconacetobacter hansenii (ATCC 23769). The strain was stored in an ultra-freezer, at $-80{ }^{\circ} \mathrm{C}$ (Nuaire), in a culture medium containing $20 \%$ glycerol, reactivated in mannitol medium, and kept on a mannitol agar plate (agar 15 $\mathrm{g} / \mathrm{L})$, at $\mathrm{pH}$ 6.5. Mannitol medium contains $25 \mathrm{~g}$ mannitol, $5 \mathrm{~g}$ yeast extract and $3 \mathrm{~g}$ peptone, dissolved in $1 \mathrm{~L}$ distilled water. The $\mathrm{pH}$ of the culture medium was previously adjusted to 6.6 and autoclaved for 20 min at $121{ }^{\circ} \mathrm{C}$.

Gluconacetobacter hansenii bacteria were reactivated in $4 \mathrm{~mL}$ of mannitol medium, and $100 \mu \mathrm{L}$ of this solution was plated on an agar-mannitol plate, and further placed in a BOD (New Ethics) incubator at $26{ }^{\circ} \mathrm{C}$ for 5 days (reactivation plate). The work and/or maintenance plates were prepared from the reactivation plate. In this respect, five colonies were isolated from the reactivation plate and resuspended in $1 \mathrm{~mL}$ of mannitol medium. To homogenize it, the solution was vortexed (Vision) for $60 \mathrm{~s}$, and then settled, before optical density (OD) reading. The reading was performed on a spectrophotometer (Molecular Devices), at $660 \mathrm{~nm}$ (reference value $\mathrm{OD}_{660}$ $=0.15$ ). After reading, a dilution to $10^{-5}$ was prepared, and $100 \mu \mathrm{L}$ of the diluted solution was plated on mannitol agar plates. The plates were kept in the BOD for seven days, at $26^{\circ} \mathrm{C}$. After the growth of the isolated colonies, the working plates were used for the $\mathrm{BNC}$ production procedure, and the maintenance plate was kept in the BOD, for up to 15 days.

To prepare the pre-inoculum, 30 colonies isolated from the working plate were inoculated in $6 \mathrm{~mL}$ of mannitol medium. The inoculum was prepared by diluting the pre-inoculum to $1: 10$ in mannitol medium. Then, $5 \mathrm{~mL}$ of the pre-inoculum was transferred and placed in $45 \mathrm{~mL}$ of mannitol medium. The inoculum was further distributed to 24-well plates, at a volume of $1 \mathrm{~mL}$ in each well. The 24-well plates were stored in 
the BOD, at $26{ }^{\circ} \mathrm{C}$, under static culture conditions, for 4 days. BNC membranes grew at the liquid/air interface. After this period, the resulted membranes were removed from the plates and taken to the subsequent purification step.

The membranes removed from the culture wells were transferred to a Schott containing a $0.1 \mathrm{M} \mathrm{NaOH}$ solution, to remove bacteria and possible residues from the culture medium and bacterial metabolism. The membranes were conditioned in the oven, at $50{ }^{\circ} \mathrm{C}$, for $24 \mathrm{~h}$. Then, the membranes were washed successively with distilled water until they reached the water $\mathrm{pH}$. Finally, the membranes were autoclaved at $121{ }^{\circ} \mathrm{C}$ for $15 \mathrm{~min}$, and kept refrigerated until use.

\section{BNC functionalization - collagen I immobilization (COL)}

The BNC was oxidized following the method of Kumar and Yang, ${ }^{29}$ with some modifications. In a fume hood, BNC was added in a 2:1 (v/v) solution of nitric acid and phosphoric acid, and then $7 \%$ sodium nitrite $(\mathrm{m} / \mathrm{v})$ was added. The solution was covered with a Petri dish to prevent the release of reaction gases into the atmosphere. The BNC membranes were reacted in this solution for $24 \mathrm{~h}$, in the absence of light, at $25{ }^{\circ} \mathrm{C}$, with slight agitation. After removal from the solution, the membranes were immersed in a $0.2 \%(\mathrm{w} / \mathrm{w})$ glycerol solution for $15 \mathrm{~min}$, to eliminate excess oxidant. Then, the membranes were washed with acetone and dried at room temperature.

After the oxidation step, chemical modifications were performed on the oxidized BNC membranes (BNC-OX) for collagen immobilization, through the derivatization method developed by Liu et al. ${ }^{30}$ and $\mathrm{Li}$ et al. ${ }^{31}$

BNC-OX membranes were immersed in $0.02 \mathrm{M}$ MES (2-morpholinoethanesulfonic acid monohydrate) $\mathrm{pH} \quad 4.5$ buffer containing EDC (1-ethyl-3-(3dimethylaminopropyl) carbodiimide)/NHS (Nhydroxysuccinimide) $0.01 \mathrm{M}(1: 1)$, for $24 \mathrm{~h}$, at $4{ }^{\circ} \mathrm{C}$, with stirring. After this time, the membranes were removed from the solution and immersed in a 0.1 $\mathrm{mg} / \mathrm{mL}$ solution of human collagen type I (SigmaAldrich), for $24 \mathrm{~h}$, at $4{ }^{\circ} \mathrm{C}$, according to Meyer et al. ${ }^{32}$

The obtained membranes were further called immobilized collagen bacterial nanocellulose membranes (BNC-COL). The remaining collagen solution was stored in a refrigerator for collagen quantification analysis. Finally, the BNC-COL membranes were washed with phosphate buffered saline (PBS), and then with deionized water.

\section{Quantitation of collagen immobilized in BNC, using Sirius red}

The amount of collagen immobilized on the BNC membrane was determined by the Sirius red method, as described by Marotta et al. ${ }^{33}$ A Sirius red solution consists of $0.1 \%$ Direct red F3B (Sigma-Aldrich) diluted in a saturated aqueous solution of picric acid.
Sirius red solution was added to the samples (1:1), which were then homogenized and allowed to stand for $30 \mathrm{~min}$. The samples were centrifuged at 10,000 rpm $\left(25^{\circ} \mathrm{C}\right.$ ) for $3 \mathrm{~min}$. The supernatants were removed, and the pellets were washed with $0.01 \mathrm{M}$ hydrochloric acid $(\mathrm{HCl})$ solution, vortexed for homogenization, and finally centrifuged at $10,000 \mathrm{rpm}\left(25^{\circ} \mathrm{C}\right)$ for $3 \mathrm{~min}$. The supernatant was discarded, and a $0.1 \mathrm{M}$ potassium hydroxide $(\mathrm{KOH})$ solution was added and allowed to react for $15 \mathrm{~min}$. Finally, the sample was transferred to a 96-well plate to read the optical density (OD) at wavelength $(\lambda)$ of $550 \mathrm{~nm}$. The standard curve was constructed using human collagen solution in the range from 0 to $0.1 \mathrm{mg} / \mathrm{mL}$.

\section{Microstructural characterization of BNC-COL}

The microstructure of the upper and lower surfaces of BNC and BNC-COL was analyzed and characterized by scanning electron microscopy (SEM), using a JEOL JSM-6390LV 10kV microscope. For SEM analysis, the hydrogels were frozen $\left(-80{ }^{\circ} \mathrm{C}\right.$ for $24 \mathrm{~h}$ ) and soon after lyophilized for $24 \mathrm{~h}$. After drying, the samples were placed in a desiccator. The lyophilized samples were fixed on carbon strips, which were glued to the aluminum stubs and finally covered with gold. Sample preparation and analysis took place at the Central Electron Microscopy Laboratory (LCME - UFSC).

\section{In vitro tests}

The adherent strain SK-MEL-28 is an example of a melanoma cell originating from Homo sapiens, isolated from a skin tumor. SK-MEL-28 cells were cultured in tissue culture dishes containing Dulbecco's modified Eagle's medium (DMEM; Gibco ${ }^{\circledR}$ Invitrogen), supplemented with $10 \%$ fetal bovine serum (SBF; Gibco ${ }^{\circledR}$ - Invitrogen), $3.7 \mathrm{~g} / \mathrm{L}$ sodium bicarbonate (Sigma-Aldrich), and $1 \%$ penicillin/streptomycin (Gibco ${ }^{\circledR}$ - Invitrogen).

Immortalized human umbilical vein endothelial cell line (HUVEC) was grown in tissue culture dishes containing Roswell Park Memorial Institute medium (RPMI; Gibco ${ }^{\circledR}$ - Invitrogen) supplemented with $10 \%$ SBF (Gibco $^{\circledR}$ - Invitrogen), $1.5 \mathrm{~g} / \mathrm{L}$ sodium bicarbonate (Sigma-Aldrich), and $1 \%$ penicillin/streptomycin $\left(\mathrm{Gibco}^{\circledR}-\right.$ Invitrogen).

Both cell lines were stored and kept in a greenhouse (Ultrasafe, $\mathrm{HF} 212 \mathrm{UV}$ ) with $5 \% \mathrm{CO}_{2}$ atmosphere, at a temperature of $37^{\circ} \mathrm{C}$, until reaching a confluence of $70-80 \%$, an ideal range for their use in experiments.

\section{SK-MEL-28 spheroids}

MicroTissues ${ }^{\circledR}$ 3D Petri Dish $^{\circledR}$ micro-mold spheroid (Sigma) molds were washed with ultrapure water and packed for autoclaving for $20 \mathrm{~min}$ at $120^{\circ} \mathrm{C}$, $1 \mathrm{~atm}$. Soon after, they were oven dried at $60^{\circ} \mathrm{C}$.

$0.9 \% \mathrm{NaCl}$ saline was prepared by weighing $0.9 \mathrm{~g}$ of $\mathrm{NaCl}$ in $100 \mathrm{~mL}$ of distilled water. Then, $2 \mathrm{~g}$ of 
UltraPure $^{\mathrm{TM}}$ Agarose was diluted in $100 \mathrm{~mL}$ of saline. The solution was heated in a microwave from $10 \mathrm{~s}$ to $10 \mathrm{~s}$, until completely homogeneous.

The $2 \%$ agarose solution in $0.9 \% \mathrm{NaCl}$ saline was completely melted in the microwave. The mold (Sigma) was placed on a sterile plate and $600 \mu \mathrm{L}$ of the $2 \%$ agarose solution in $0.9 \% \mathrm{NaCl}$ saline was pipetted and allowed to solidify for $10 \mathrm{~min}$. After that, the mold was detached and distributed with the aid of sterile forceps over the 12-well plate wells. The mold was fixed to the well by placing $700 \mu \mathrm{L}$ of $2 \%$ agarose solution in $0.9 \% \mathrm{NaCl}$ saline around the mold. The molds were UV sterilized at $30 \mathrm{~min}$.

After sterilization, the molds were equilibrated with DMEM base culture medium $(1.5 \mathrm{~mL} /$ well of the $12-$ well plate) and incubated in a $5 \% \mathrm{CO}_{2}$ oven, at $37{ }^{\circ} \mathrm{C}$, for $15 \mathrm{~min}$ or more. The medium was removed and added again to equilibrate once more.

SK-MEL-28 cells grown in tissue culture dishes reached $80 \%$ to $90 \%$ confluence, forming a cell monolayer. The cell monolayer was trypsinized using $1 \mathrm{~mL}$ of Trypsin $\left(\mathrm{Gibco}^{\circledR}\right)$, and the cell suspension was quantified using a Neubauer chamber (SP LABOR). The cells were centrifuged, the supernatant was removed, and they were resuspended in DMEM medium $\left(1 \times 10^{6}\right.$ SK-MEL-28 cells in $120 \mu \mathrm{L}$ of DMEM medium). The DMEM medium was removed from the molds and they were placed in the $5 \% \mathrm{CO}_{2}$ oven, at $37{ }^{\circ} \mathrm{C}$, for $10 \mathrm{~min}$ to dry completely. $1 \times 10^{6}$ SK-MEL-28 cells were resuspended in $120 \mu \mathrm{L}$ of DMEM medium, plated in the center of each mold and kept in the $5 \% \mathrm{CO}_{2}$ oven, at $37^{\circ} \mathrm{C}$. After $3 \mathrm{~h}, 1 \mathrm{~mL}$ of DMEM medium was added to each well and placed in the $5 \% \mathrm{CO}_{2}$ oven, at $37{ }^{\circ} \mathrm{C}$. DMEM medium was changed every 24 hours, until 48 hours.

The spheroids were produced and removed from the micromold by jetting with $1 \mathrm{~mL}$ of PBS (Gibco ${ }^{\circledR}$ ) placed in $1.5 \mathrm{~mL}$ Eppendorfs. The spheroids decanted at the bottom of the Eppendorfs and thus PBS was removed.

\section{Spheroid cell viability}

Cellular metabolic activity of spheroids was evaluated by the MTS [3-(4,5-dimethylthiazol-2-yl)-5(3-carboxymethoxyphenyl)-2-(4-sulfophenyl)-2H-

tetrazolium] assay (Promega), at three times: $24 \mathrm{~h}, 48 \mathrm{~h}$ and $72 \mathrm{~h}$ after SK-MEL-28 cells were plated on agarose templates. The spheroids were removed from the mold, three were added to each well of a 96-well plate, and $100 \mu \mathrm{L}$ of DMEM culture medium and 20 $\mu \mathrm{L}$ of MTS reagent were placed in each well. The spheroids were kept in a greenhouse with a $5 \% \mathrm{CO}_{2}$ atmosphere, at $37{ }^{\circ} \mathrm{C}$, for $2 \mathrm{~h}$. Thereafter, the wells were homogenized and $100 \mu \mathrm{L}$ of the solution was transferred to a new well of another 96-well plate, and thus the absorbance reading was performed at $490 \mathrm{~nm}$.

\section{Live/dead assay}

The spheroids were removed with PBS jets from the mold after 2 days of culture and placed in Eppendorfs. PBS was removed and $500 \mu \mathrm{L}$ of incomplete medium, plus $100 \mu \mathrm{L}$ of PBS solution of ethidium homodimer-1 and calcein (Invitrogen), were added to the spheroids, and allowed to work for $45 \mathrm{~min}$. Then, the spheroids were visualized in an Olympus BX41 Fluorescence Microscope, at the Multipurpose Laboratory of Biology Studies (LAMEB - UFSC).

\section{Bright-field microscopy}

The spheroids were fixed with a $4 \%$ paraformaldehyde solution for $12 \mathrm{~h}$ at three different fixation times: $24 \mathrm{~h}, 48 \mathrm{~h}$ and $72 \mathrm{~h}$. After that, the spheroids were washed with PBS three consecutive times and kept in a refrigerator at $4{ }^{\circ} \mathrm{C}$, immersed in PBS, until the day the images were taken. The images were captured with an Olympus BX41 Microscope, at the Multipurpose Laboratory of Biology Studies (LAMEB - UFSC).

Co-cultivation of SK-MEL-28 spheroids and HUVECs cells on BNC-COL hydrogels, under bright-field microscopy

The HUVECs were co-cultured with SK-MEL-28 spheroids on the lower side of the BNC-COL layer, under the following conditions: HUVEC cells were cocultured simultaneously with SK-MEL spheroids at a density of $5.2 \times 10^{4}$ HUVEC cells/ $/ \mathrm{cm}^{2}$ and 28 SK-MEL28 spheroids $/ \mathrm{cm}^{2}$. They were stored in a $5 \% \mathrm{CO}_{2}$ oven, at $37{ }^{\circ} \mathrm{C}$, for 3 days, with $500 \mu \mathrm{L}$ of DMEM medium per well (24-well plate), and the medium was changed every $48 \mathrm{~h}$. After the samples were fixed with $4 \%$ paraformaldehyde, they were washed three times in PBS, and kept immersed in PBS in the refrigerator, at $4{ }^{\circ} \mathrm{C}$. Bright-field images were taken with an Olympus IX83 Microscope at LAMEB - UFSC.

\section{Statistical analysis}

Data were statistically analyzed using Origin software, version Pro 8.0. The results were presented as mean \pm standard deviation of the mean and compared by univariate analysis of variance (one-way ANOVA) and Tukey test, which considers statistically significant values when $\mathrm{p}<0.05$.

\section{RESULTS AND DISCUSSION} BNC functionalization and characterization

BNC was oxidized to convert free hydroxyl groups to carboxyl groups, by the addition of $\mathrm{HNO}_{3} / \mathrm{H}_{3} \mathrm{PO}_{4}-\mathrm{NaNO}_{2}$, resulting in oxidized BNC (BNC-OX) in $\mathrm{C}_{6}$ carbon. These carboxyl groups were activated with EDC (binding agent), allowing cross-linking between the active carboxyl groups of BNC-OX with the collagen type I amine groups, resulting in the covalent immobilization of collagen (BNC-COL). 
The upper and lower surface microstructure of the BNC and BNC-COL hydrogels were analyzed by scanning electron microscopy (SEM). The upper surface of the BNC was characterized by a tangle of densely and compactly arranged 3D nanofibers with non-significant pores (Fig. 1), as also observed in a previous work. ${ }^{34}$ This surface is formed in bacterial culture at the air interface. ${ }^{35}$ The bottom surface of the BNC was defined by a latticed 3D nanofiber network with interconnected pores. According to Klemm et al. ${ }^{24}$ the bottom surface is more porous. It is formed in bacterial culture at the liquid interface or submerged in the culture medium. ${ }^{35}$

SEM micrographs of the upper surface of the BNC-COL hydrogels show that the nanofibers remained arranged in the same arrangement as that observed on the upper surface of the BNC hydrogels. After oxidation, the BNC fibers became thinner and showed a rough and slightly curved aspect, but the three-dimensional nanofiber lattice structure of BNC was preserved in BNC-COL. ${ }^{36}$ The SEM image of the BNCCOL surface shows that collagen homogeneously filled the BNC structure. ${ }^{37}$ After treatment with the collagen solution, the BNC morphology showed some changes. Nanofibers can still be visualized on the surface, but they have largely formed a smooth layer, thanks to the penetration of collagen molecules into the BNC nanofibers. ${ }^{38}$

\section{Quantitation of collagen immobilized in BNC, using Sirius red}

Quantitative collagen analysis was performed using the Sirius red method. The Sirius red colorimetric assay is commonly used to measure the amount of soluble collagen in stock solutions. ${ }^{39}$ The results of the analysis are shown in Figure 2. The concentration of collagen in the initial solution, in which the BNC-OX membranes were inserted, was $0.06751 \mathrm{mg} / \mathrm{mL}$, and in the final solution, the remaining collagen was of $0.03245 \mathrm{mg} / \mathrm{mL}$. This means that 0.03506 $\mathrm{mg} / \mathrm{mL}$, just over $50 \%$ of the initial collagen amount, was retained in the membranes, either by immobilization or incorporation.

Most 3D artificial constructs that mimic in vivo tissues are manufactured using low amounts of collagen $(4 \mathrm{mg} / \mathrm{mL})$ in hydrogels, and most publications use around $2 \mathrm{mg} / \mathrm{mL}$. The use of these concentrations is mainly due to the commercially available collagen formulations, which are sold at low concentrations. ${ }^{39}$ Ramanujan et al. ${ }^{40}$ and Erikson et $a .^{41}$ evaluated the effect of different collagen concentrations on fiber diffusivity and structure, and found a decrease in diffusion rate and fiber length and organization with increasing collagen concentration.

\section{Production and characterization of spheroids}

The spheroids were produced according to the method developed and described previously. The spheroids were removed from the molds after three formation times: 1,2 and 3 days, and evaluated for cell viability and morphology.

The morphology of the spheroids at the three formation times is shown in Figure 3. It can be noted that on the first day of formation, the spheroids are not well defined, their structure is not yet completely rounded and therefore they have an irregular border. On the second day, they have a more defined, homogeneous, and regular structure, as well as on the third day, when the spheroids were well formed and established.

Gitschier et $a l .^{42}$ reported similar results. Spheroids with $24 \mathrm{~h}$ formation had poorly defined edges. After $48 \mathrm{~h}$ of formation, it was observed that the spheroids were more compacted and with defined edges. 80 hours after the initiation of aggregation, the center of the spheroid showed early signs of necrosis. According to Zanoni et $a l .,{ }^{10}$ the growth of spheroids, just like the solid tumors, begins with an increase in volume followed by spheroidization, where spheroids become more regular and decrease in volume until they reach equilibrium, which is an indispensable phase for the organization of the complex structural and functional spheroids. ${ }^{10}$ Figure 4 shows the results of the live/dead assay on the second day of formation and reaffirms what was found under bright-field microscopy. A more defined structure and greater presence of dead cells can be perceived, especially in the spheroid nucleus. The location of dead cells within the tumor nucleus can be attributed to restricted nutrient transport, as also happens in vivo. ${ }^{8}$

Cell viability on the three days of formation was quantitatively determined by the MTS assay. The result is visualized in Figure 5. The results showed that there is no significant difference in cell viability over the three days, that is, despite showing morphological and structural differences, the spheroids have the same concentration of viable cells. 


\section{MAIIRA DE ANDRADE PEIXOTO et al.}

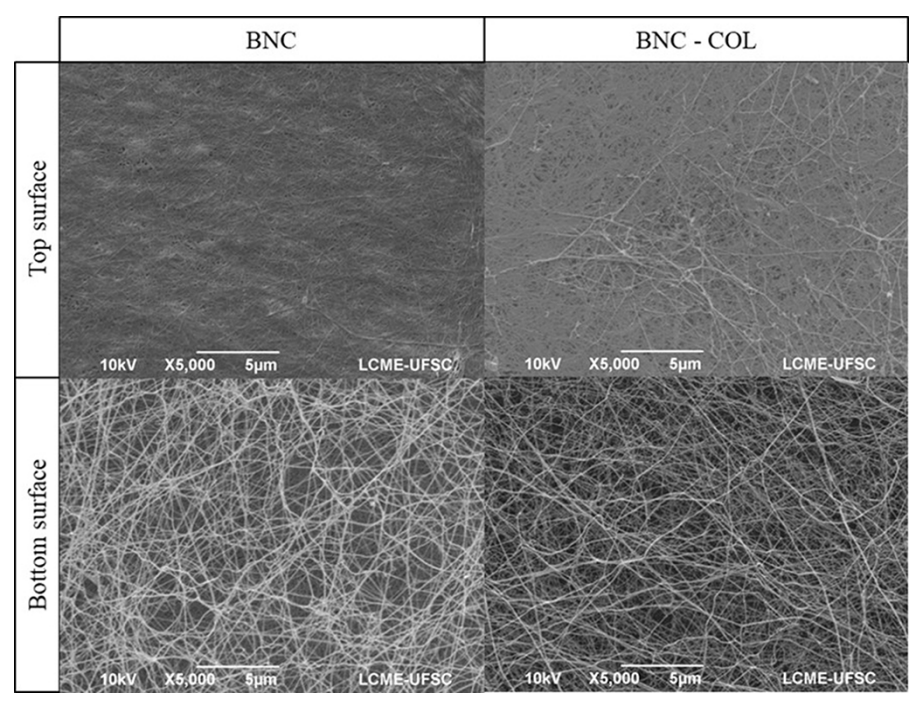

Figure 1: SEM micrographs of freeze-dried BNC and BNC-COL

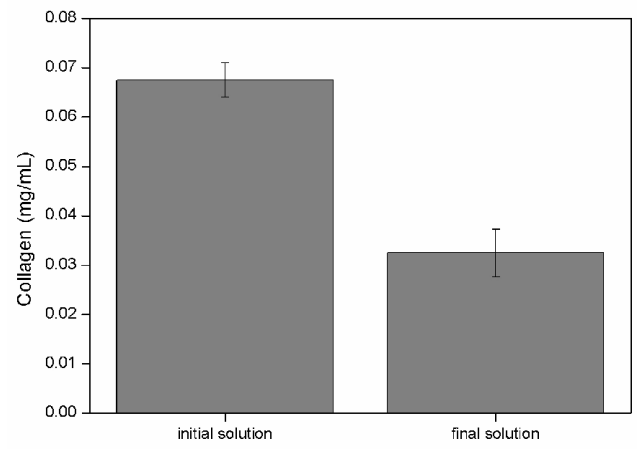

Figure 2: Collagen concentration in initial and final solution; results expressed in $\mathrm{mg} / \mathrm{mL}$ (mean \pm standard deviation, $\mathrm{n}=3$ )

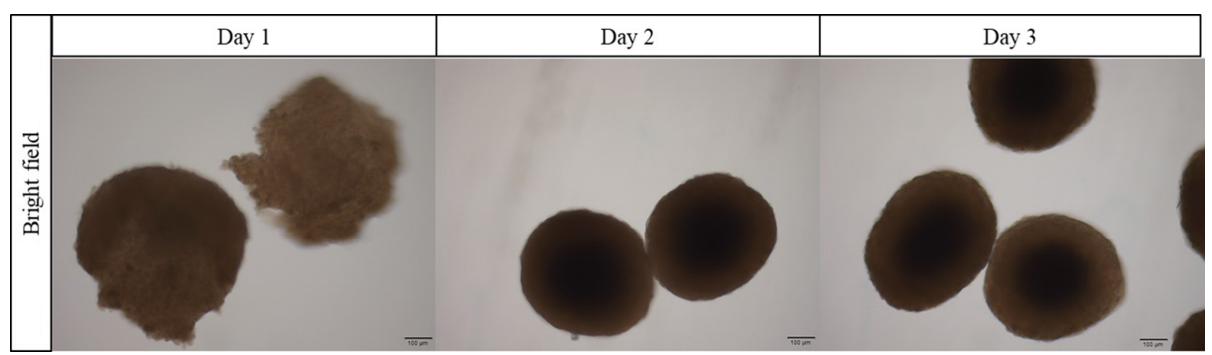

Figure 3: Melanoma spheroid morphology in the three times of formation in bright field microscopy 


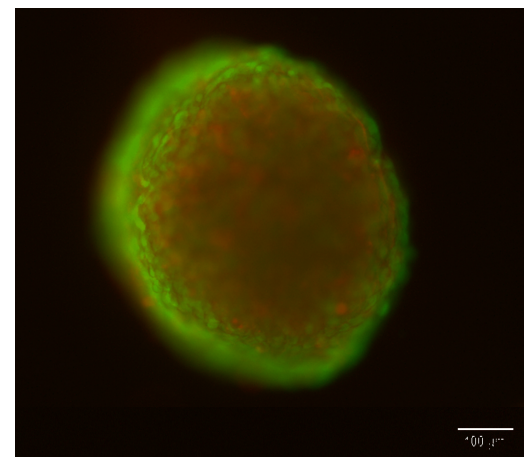

Figure 4: Melanoma spheroid fluorescence image (live/dead assay)

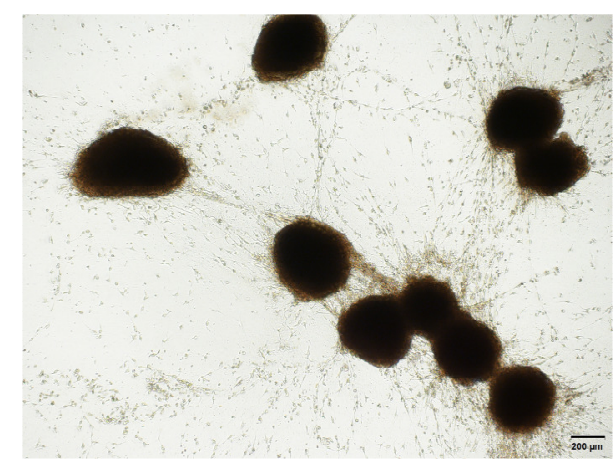

Figure 6: Co-cultivation of SK-MEL-28 HUVECs and spheroid cells in BNC-COL hydrogels under bright-field microscopy

\section{Co-cultivation of SK-MEL-28 HUVECs and spheroid cells in BNC-COL hydrogels under bright-field microscopy}

On the upper surface of the BNC, there was poor cell adhesion and the cells were less spread out and more rounded. On the lower side, a more adherent behavior was observed, that is, a larger number of viable HUVECs may be associated with porosity, since the fiber network arrangement, or density, may be a factor responsible for the different behavior of HUVEC, on both sides of the BNC membrane. ${ }^{43}$

When HUVECs were cultivated in BNC-COL, a differentiated behavior occurred, with greater adhesion on both sides. Especially on the underside, it was possible to notice more spread and adhered cells, showing a different cellular behavior from the other surfaces (Fig. 6). Solouk et $a .^{44}$ found that collagen immobilization was beneficial for endothelial cell fixation, i.e. COLP-NC showed better cell compatibility compared to collagen-free surfaces, such as polyhedral

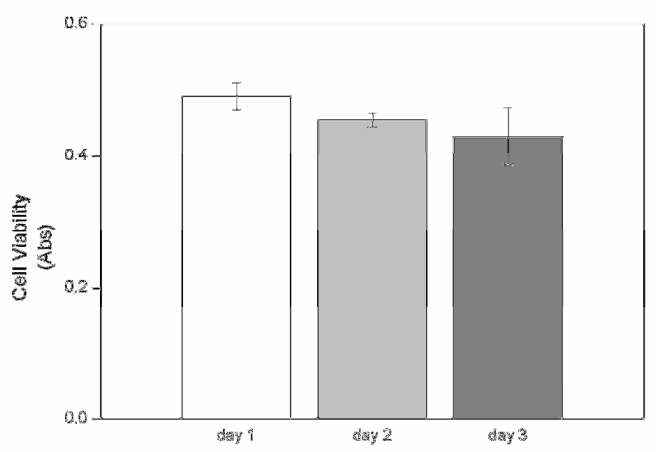

Figure 5: Cell viability on days 1, 2 and 3 of spheroid formation, by the MTS method (results expressed as mean \pm standard deviation)

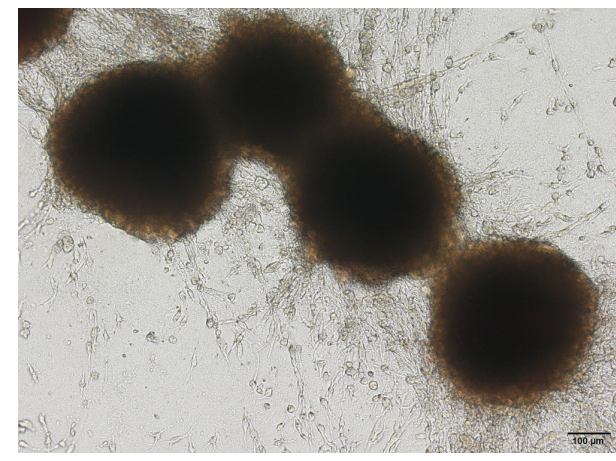

Figure 7: SK-MEL-28 spheroids on the bottom surface of BNC-COL hydrogels

oligomeric silsesquioxane (POSS) and polyurethane cationomer (PUC) nanocomposite (NC), and plasma activated nanocomposite (P$\mathrm{NC})$.

Nguyen et $a l^{45}$ noted that when cultivating HUVECs and hMSCs cells in alginate and collagen scaffolds in vitro, they had the native behavior found in vivo. When cells were seeded on flat discs of alginate hydrogels, hMSCs remained with rounded morphology and poor adhesion, as did HUVECs. On the other hand, a larger number of cells adhered to collagen hydrogels for both hMSCs and HUVECs, with larger numbers of elongated morphology HUVECs.

Most SK-MEL-28 spheroids failed to adhere to the upper surface of the BNC, but the few that adhered did not migrate to the membrane surface. On the underside of the BNC, the spheroids also adhered to a lesser extent, but it was possible to see a small migration of SK-MEL-28 cells migrating from the spheroid to the surface of the 
BNC. Reis et al. ${ }^{46}$ found that, when cultured in BNC, melanoma cells (SK-MEL-28) had more cell-cell interaction than hydrogel-cell, so that melanoma cells eventually organized themselves as tumor masses.

In the BNC-COL membrane, SK-MEL-28 spheroids showed greater adhesion and cell migration on both the upper and lower surfaces, and thus the spheroids revealed a more invasive character (Fig. 7). Adhesion between collagen and cancer cells, such as COL I and COL IV adhesion, affects cancer progression. ${ }^{9}$ Spheroids adhere to fibronectin and type I collagen more strongly than laminin and collagen $\mathrm{IV}^{47}$ Miskolczi et $a l .^{48}$ evaluated the influence of collagen gels rigidity on the regulation of melanoma cell adhesion and found that cells, when cultured on several collagen gels, show different rounder and less adherent morphologies in a $0.2 \mathrm{kPa}$ stiff gel, and more spread according to increased stiffness.

Shoval et al $^{49}$ found that melanoma cells (A375) are highly invasive when cultured in collagen. In fact, they developed heterospheroids with HUVEC cells and different other tumor cells, such as melanoma cells (A375), pancreatic tumor cells (PANC1 and BxPC3), and breast cancer cells (MDA-MB-231), and found that with higher concentration of HUVEC in the tumor, spheroids produce rougher margins as cells "sprout" or detach from the central aggregate, suggesting greater invasion potential.

\section{CONCLUSION}

Collagen was chemically immobilized on BNC hydrogels. The behavior of HUVEC cells and SK-MEL-28 spheroids was dependent on microstructure and chemical composition. Human melanoma cell spheroid formation in agarose molds has been established. On the second day of formation, the spheroid showed a more compact and established structure with rounded edges. Cell behavior and morphology were evaluated on both sides of BNC and BNC-COL hydrogels, exhibiting a different behavior when cells were cultured on the bottom surface of BNC-COL. Tumor cell migrations from the spheroids towards the matrix were observed. Therefore, the platform developed in this work is conducive to cellular behavior studies and can be a useful tool for drug screening.

ACKNOWLEDGMENTS: The authors thank the CAPES, Brazil, for the financial support. The authors also thank the Analytical Laboratory units at the Federal University of Santa Catarina (UFSC), LCME, LAMEB and EQA.

\section{REFERENCES}

1 INCA - Instituto Nacional De Câncer, Câncer de pele melanoma (2020), https://www.inca.gov.br/tiposde-cancer/cancer-de-pele-melanoma

2 INCA - Instituto Nacional de Câncer, Incidência de Câncer no Brasil (2018), https://www.inca.gov.br/estimativa/introducao

3 J. Klicks, C. Maßlo, A. Kluth, R. Rudolf and M. Hafner, BMC Cancer, 19, 402 (2019), https://doi.org/10.1186/s12885-019-5606-4

4 C. Herraiz, C. J. Cervantes, B. S. Laorden and J. C. García-Borrón, Semin. Cell. Dev. Biol., 78, 73 (2017), https://doi.org/10.1016/j.semcdb.2017.06.021

5 J. Folkman, N. Engl. J. Med., 285, 1182 (1971), https://doi.org/10.1056/NEJM197111182852108

6 M. S. L. Pinho, Rev. Bras. Coloproct., 25, 369 (2005),

https://www.sbcp.org.br/revista/nbr254/P396_402.htm

7 A. W. Holle, J. L. Young and J. P. Spatz, $A d v$. Drug Deliv. Rev., 97, 270-9 (2015), https://doi.org/10.1016/j.addr.2015.10.007

8 S. P. Lamichhane, N. Arya, E. Kohler, S. Xiang, J. Christensen et al., BMC Cancer, 16, 581 (2016), https://doi.org/10.1186/s12885-016-2634-1

9 S. Xu, H. Xu, W. Wang, S. Li, Hao Li et al., J. Transl. Med., 17, $309 \quad$ (2019), https://doi.org/10.1186/s12967-019-2058-1

10 M. Zanoni, S. Pignatta, C. Arienti, M. Bonafe and A. Tesei, Expert Opin. Drug Discov., 14, 289 (2019), https://doi.org/10.1080/17460441.2019.1570129

11 D. Antoni, H. Burckel, E. Josset and G. Noel, Int. J. Mol. Sci., 16, 5517 (2015), https://doi.org/10.3390/ijms16035517

12 X. Gong, C. Lin, J. Cheng, J. Su, H. Zhao et al., Plos One, (2015), https://doi.org/10.1371/journal.pone.0130348

13 W. C. Hsiao and T. H. Young, J. Formos. Med. Assoc., $\quad \mathbf{1 1 8 ,} 152 \quad$ (2019), https://doi.org/10.1016/j.jfma.2018.02.010

14 G. Lazzari, V. Nicolas, M. Matsusaki, M. Akashi, P. Couvreur et al., Acta Biomater., 78, 296 (2018), https://doi.org/10.1016/j.actbio.2018.08.008

15 H. H. Song, K. M. Park and S. Gerecht, Adv. Drug Deliv. Rev., $\quad 79, \quad 19 \quad$ (2014), https://doi.org/10.1016/j.addr.2014.06.002

16 G. Benton, I. Arnaoutova, J. George, H. K. Kleinman and J. Koblinski, Adv. Drug Deliv. Rev., 79, 3 (2014), https://doi.org/10.1016/j.addr.2014.06.005

17 M. Vinci, C. Box and S. A. Eccles, J. Vis. Exp., 99, 52686 (2015), https://doi.org/10.3791/52686

18 C. S. Hughes, L. M. Postovit and G. A. Lajoie, Proteomics, 10, $1886 \quad$ (2010), https://doi.org/10.1002/pmic.200900758 
Biol., $\quad \mathbf{1 5}, \quad 378 \quad$ (2005), https://doi.org/10.1016/j.semcancer.2005.05.004

20 I. M. El-Sherbiny and M. H. Yacoub, Glob. Cardiol. Sci. Pract., 2013, 316 (2013), https://doi.org/10.5339/gcsp.2013.38

21 J. S. Miller, C. J. Shen and W. R. Legant, Biomaterials, $\quad \mathbf{1 3}, \quad 3736 \quad$ (2010), https://doi.org/10.1016/j.biomaterials.2010.01.058

${ }^{22}$ C. R. Rambo, D. O. S. Recouvreux and C. A. Carminatti, Mater. Sci. Eng.: C, 28, 549 (2008), https://doi.org/10.1016/j.msec.2007.11.011

${ }^{23}$ J. K. Park, Y. H. Park and J. Y. Jung, Biotechnol. Bioprocess. $\quad$ Eng., $\quad 8, \quad 83 \quad$ (2003), https://doi.org/10.1007/BF02940261

${ }^{24}$ D. Klemm, F. Kramer, S. Moritz, T. Lindstrom, M. Ankerfors et al., Angew. Chem. Int. Ed., 50, 24 (2011), https://doi.org/10.1002/anie.201001273

25 A. F. Karamysheva, Biochemistry (Moscow), 73, 751

(2008), https://doi.org/10.1134/S0006297908070031

26 J. L. Drury and D. J. Mooney, Biomaterials, 24, 4337

https://doi.org/10.1016/S01429612(03)00340-5

(2003),

27 O. Oliviero, M. Ventre and P. A. Netti, Acta

$\begin{array}{llll}\text { Biomater., } & \mathbf{8}, & 3294 & \text { (2012), }\end{array}$ https://doi.org/10.1016/j.actbio.2012.05.019

28 R. P. Bareil, R. Gauvin and F. Berthod, Materials

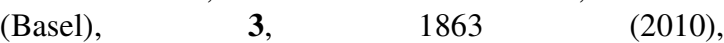
https://doi.org/10.3390/ma3031863

29 V. Kumar and T. Yang, Carbohyd. Polym., 48, 403 (2002), https://doi.org/10.1016/S01448617(01)00290-9

30 T. Y. Liu, W. C. Lin and L. Y. Huang, Biomaterials, $\quad \mathbf{2 6}, \quad 1437 \quad$ (2005), https://doi.org/10.1016/j.biomaterials.2004.04.039

31 W. Li, Y. Guo, H. Wang, D. Shi, C. Liang et al., J. Mater. Sci. Mater. Med., 19, 847 (2007), https://doi.org/10.1007/s10856-007-3087-5

32 A. C. Meyer, E. M. dos Reis, L. M. Porto, in Procs. Congresso Brasileiro de Engenharia Química em Iniciação Científica (Blucher Chemical Engineering Proceedings), 2017, vol. 1, p. 160-165, https://doi.org/10.5151/chemeng-cobeqic2017-113

33 M. Marotta and G. Martino, Anal. Biochem., 150, 86

https://doi.org/10.1016/00032697(85)90443-9

(1985),

34 E. M. dos Reis, PhD Thesis, Universidade Federal de Santa Catarina, 2016, https://repositorio.ufsc.br/xmlui/handle/123456789/17 6645

35 F. V. Berti, PhD Thesis, Universidade Federal de Santa Catarina, 2012, https://repositorio.ufsc.br/xmlui/bitstream/handle/1234 56789/96407/310455.pdf? sequence $=1$

36 X. Wen, Y. Zheng and J. Wu Int. J. Nanomed., 10, 4623 (2015), https://doi.org/10.2147/IJN.S84452

37 S. Saska, L. N. Texeira, P. T de Oliveira, A. M. Minarelli Gaspar, S. J. Lima Ribeiro et al., J. Mater.
Chem., 22, $\quad 41 \quad$ (2012), https://doi.org/10.1039/C2JM33762B

38 C. Zhijiang and Y. Guang, J. Appl. Polym. Sci., 120, 5 (2011), https://doi.org/10.1002/app.33318

39 E. E. Antoine, P. P. Vlachos and M. N. Rylander, Tissue Eng., B Rev., 20, 683 (2014), https://doi.org/10.1089/ten.TEB.2014.0086

40 S. Ramanujan, A. Pluen, T. D. McKee, E. B. Brown, Y. Boucher et al., Biophys. J., 83, 1650 (2002), https://doi.org/10.1016/S0006-3495(02)73933-7

41 A. Erikson, H. N. Andersen, S. N. Naess, P. Sikorski et al., Biopolymers, 89, 2 (2007), https://doi.org/10.1002/bip.20874

${ }^{42}$ H. Gitschier, Y. Fang and R. M. Eglen, Drug Discov. World, 2017, 55 (2017)

43 F. V. Berti, C. R. Rambo, P. F. Dias and L. M. Porto, Mater. Sci. Eng. C Mater. Biol. Appl., 33, 4684 (2013), https://doi.org/10.1016/j.msec.2013.07.029

44 A. Solouk, H. Mirzadeh and M. A. Shokrgozar, Iran. Biomed. J., 15, 6 (2011), PMID: 21725494

45 B. N. B. Nguyen, R. A. Moriarty and T. Kamalitdinov, J. Biomed. Mater. Res. A., 105, 1123 (2017), https://doi.org/10.1002/jbm.a.36008

46 E. M dos Reis, F. V. Berti, G. Colla and L. M. Porto, J. Biomed. Mater. Res. B Appl. Biomater., 106, 2741 (2018), https://doi.org/10.1002/jbm.b.34055

47 K. M. Tevis, Y. L. Colson and M. W. Grinstaff, Adv. Biosyst., 1, $1700083 \quad$ (2017), https://doi.org/10.1002/adbi.201700083

48 Z. Miskolczi, M. P. Smith, C. Wellbrock, J. Ferguson, J. Barriuso et al., Oncogene, 37, 3166 (2018), https://doi.org/10.1038/s41388-018-0209-0

49 H. Shoval, A. K. Bluman, O. Benny, T. Stern, G. Zamir et al., Sci. Rep., 7, 10428 (2017), https://doi.org/10.1038/s41598-017-10699-y 